Portland State University

PDXScholar

\title{
BAKENEKO: a Look into the Origins of Japan's Supernatural Cats
}

Cedar Taulbee

Portland State University

Follow this and additional works at: https://pdxscholar.library.pdx.edu/honorstheses

Part of the Folklore Commons, Graphic Design Commons, and the Japanese Studies Commons Let us know how access to this document benefits you.

\section{Recommended Citation}

Taulbee, Cedar, "BAKENEKO: a Look into the Origins of Japan's Supernatural Cats" (2021). University Honors Theses. Paper 965.

https://doi.org/10.15760/honors.989

This Thesis is brought to you for free and open access. It has been accepted for inclusion in University Honors Theses by an authorized administrator of PDXScholar. Please contact us if we can make this document more accessible: pdxscholar@pdx.edu. 


\section{2n}

min n้ man nnann nैân min 


\section{BAKENEKO}

A look into the origins of Japan's supernatural cats 


\section{Acknowledgments}

(C) 2021, Cedar Taulbee

Bakeneko: A look into the origins of Japan's supernatural cats

Cedar Taulbee - First Edition

BOOK AND COVER DESIGNED BY

Cedar Taulbee

ILLUSTRATED BY

Cedar Taulbee
Thanks to my family: Taffy Taulbee, Carsen Taulbee, and Cullen Taulbee. Thanks to Sean Schumacher, my advisor, and to Zack Davisson, whose expertise helped make this book possible. And a big thanks to Mayo, my mom's cat, who inspired me to create this book and whose image appears countless times in its pages.

This book was created as a senior thesis to complete a Bachelor's of Arts in Graphic Design for Portland State University's Honors College, under the advising of Sean Schumacher. 


\section{Table of Contents}

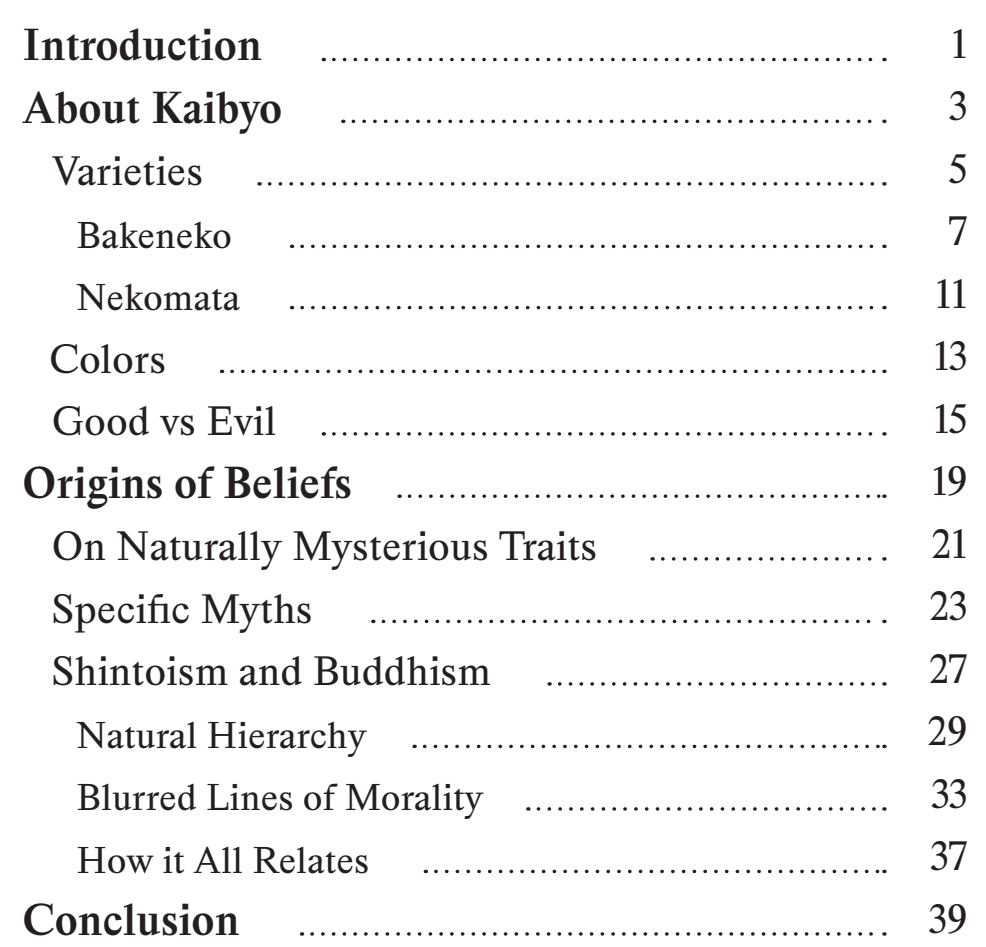

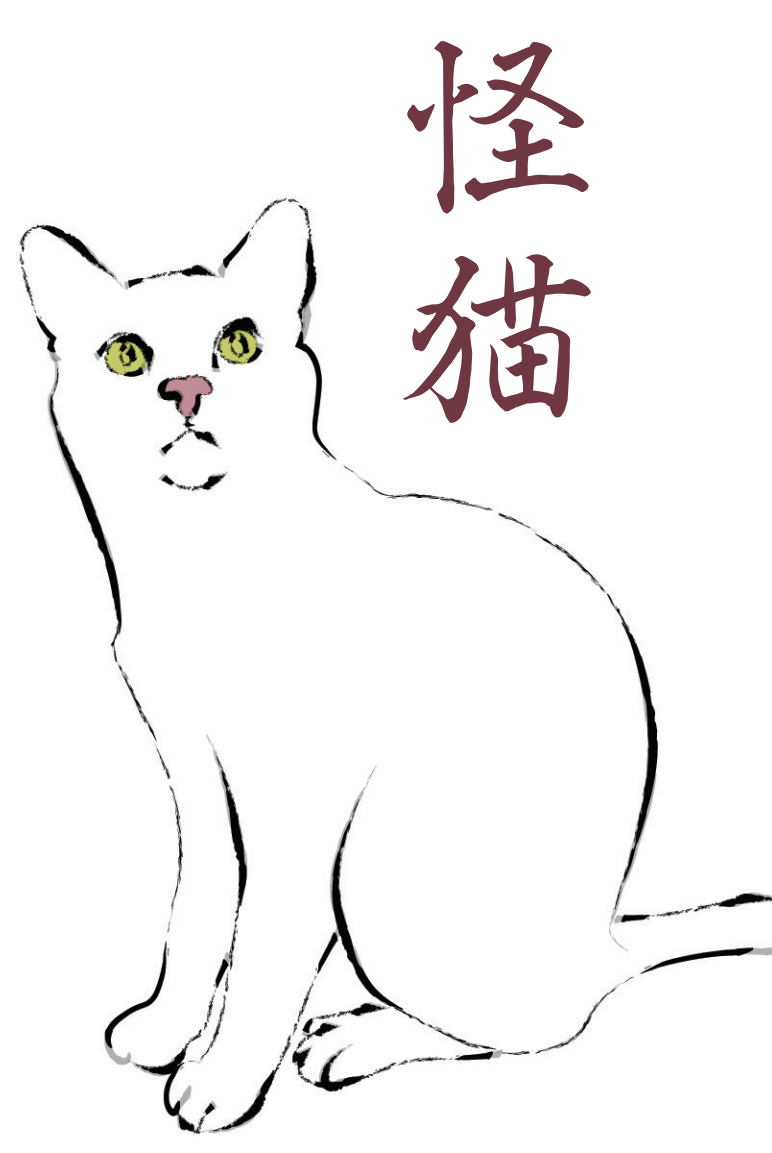




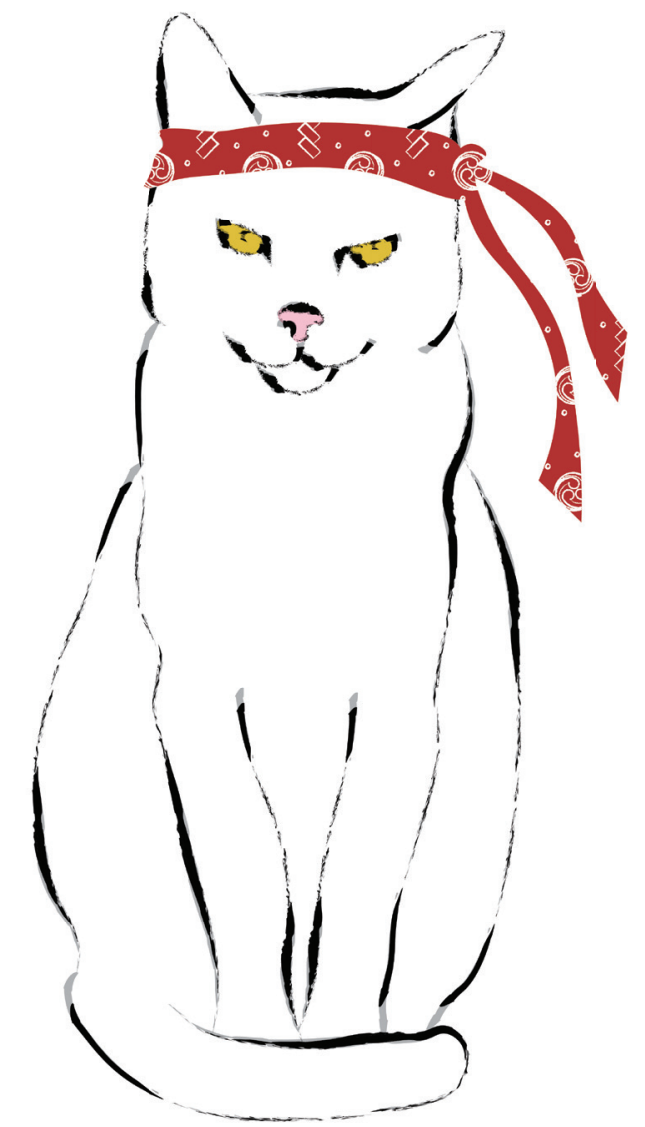

\section{Introduction}

Cats are strange and mysterious creatures. Cultures all around the world have created myths and legends surrounding house cats, stories laden with superstition and und ing hou cats, stories laden whe a touch of fear. In their association with witches and black magic. In Ancient Egypt, as most of us know, cats were worshipped as sacred animals. And in Japan there are bakeneko.

I use bakeneko as a general term, but what I am really referring to is kaibyo, which is a Japanese word used to describe supernatural or "strange" cats. And Japan has a lot of them. Almost since cats were first introduced to the archipelago in the mid-800s, stories have come about of their strange powers, their propensities toward shape-shifting, and all other sorts of strange myths.

But if you're like me, you may be wondering: why? What about cats and culture in general has led to this inevitable fascination, and sometimes demonization, of our domestic feline friens? The mere I read about these legends, the mic I wondered on the questions, and the deeper I hat to wondered on these questions, and the deeper I had to go to find the answers. So join me in looking at the origins of these strange cats, and the underlying factors that have helped form Japan's complicated relationship with these mysterious and wonderful cats. 


\section{About haibyo}

One could use the word bakeneko, meaning "change cat" to describe Japan's variety of superaturet all of "changed thing," is bake mono, meaning "changed things," is a term commonly used to describe various spirits and monsters in Japanese mythology. But a more fitting term might be kaibyo, which literally translates to "strange cats."

And strange they are. From the bakeneko which wears a human towel on its head and transforms into beautiful women on command, to the fearsome nekomata, the split-tailed cat that can reach truly monstrous sizes, Japan's mythology has a menagerie of supernatural cats, both good, evil, and shrouded in mystery.

So let's take a look at the many strange cats which Japan's folklore has to offer. The legends that surround them, the various legends that surround them, the various
superstitions, and the observed characteristics of these supernatural felines.

$v^{2}=040$

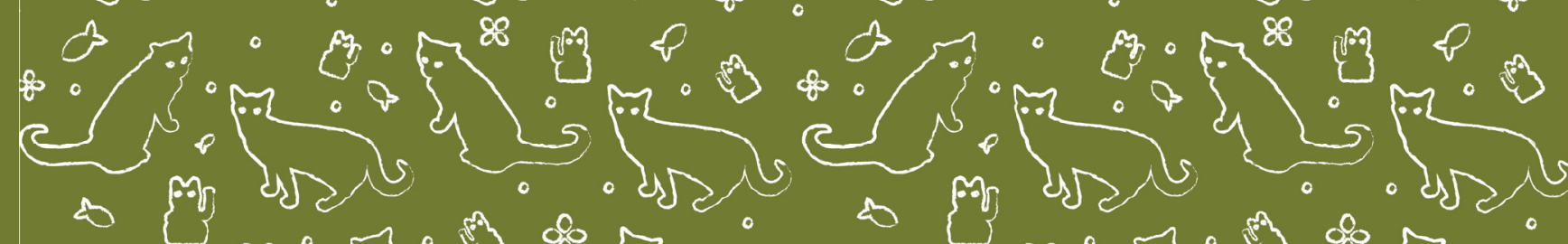

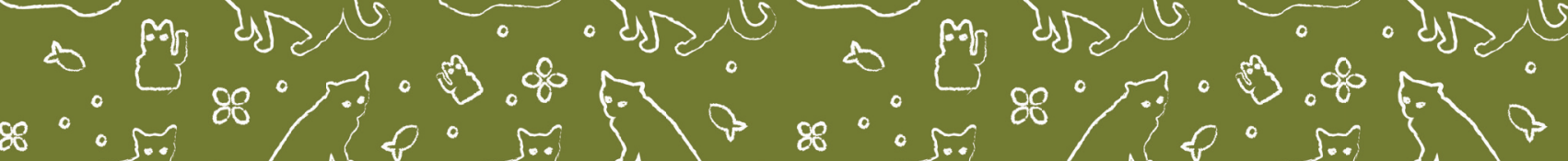

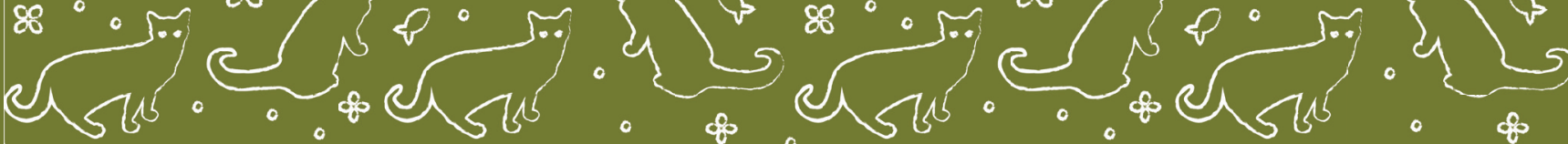

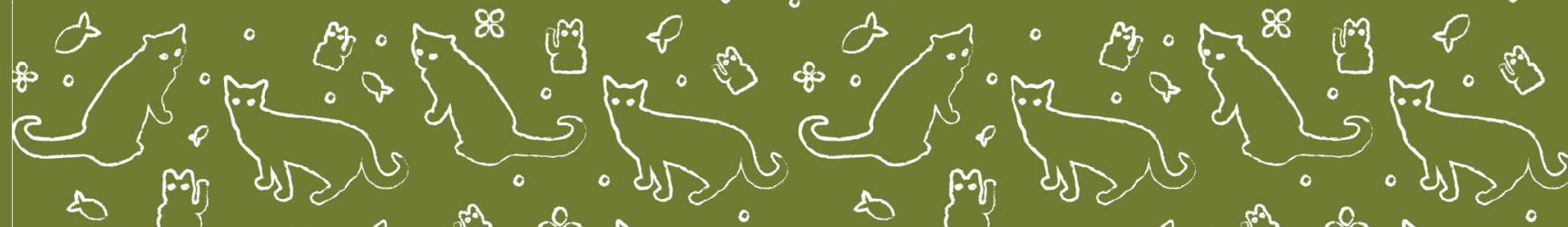
作

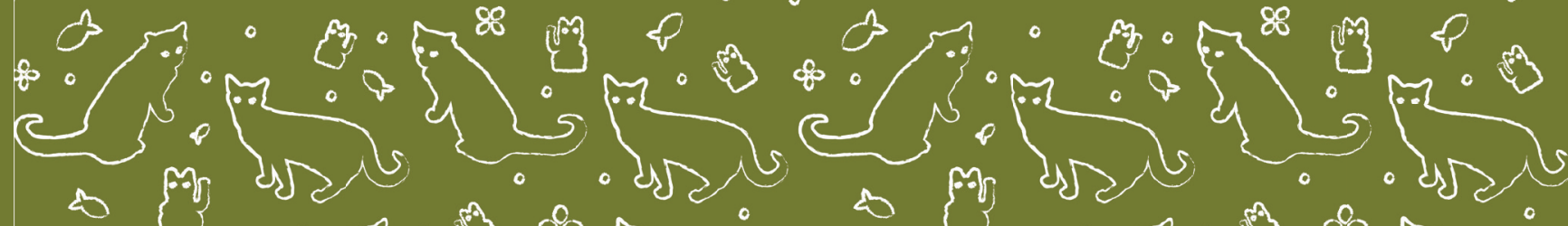

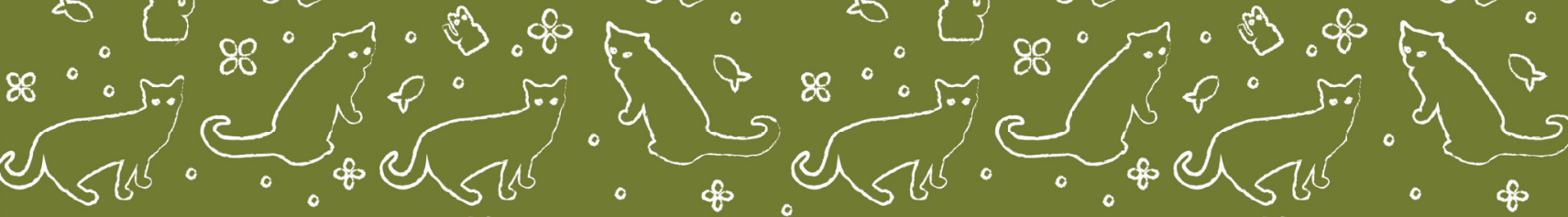

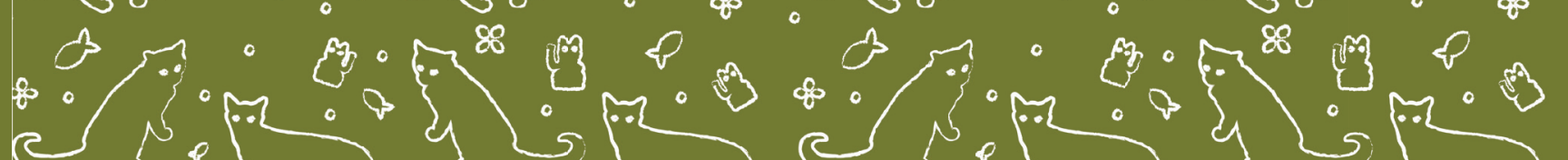




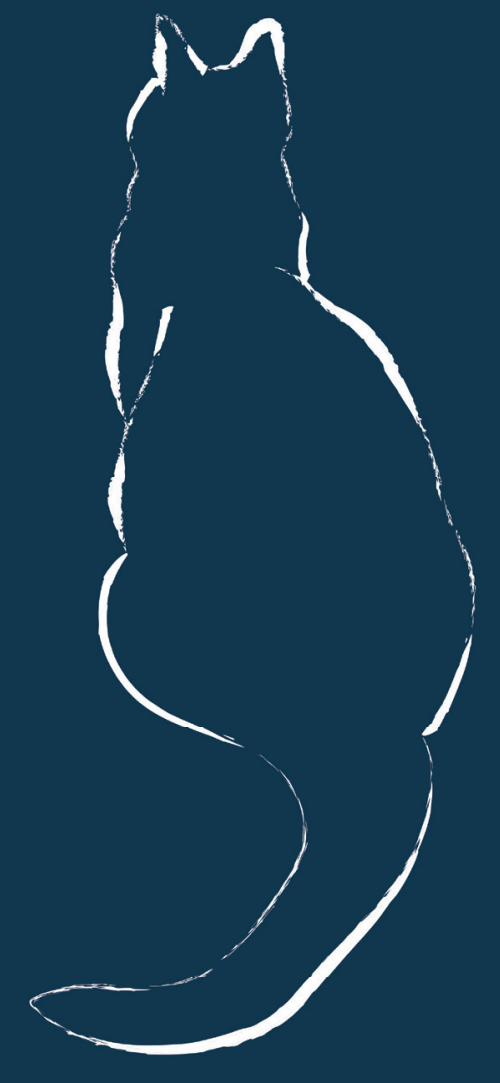

Although there is a wide variety of different kinds of superof them are quite
of A specific, and the majority of then can fall into the same natural cats. For that reason, I will be focusing on supernatural cats. For that reason, I will be focusing on the two most commonly referenced supernatural cats in Japanese folklore. The first is the bakeneko, or "change cat," and the second is the nekomata, which is commonly translated to "split cat." In some stories the lines between these creatures fade, and bakeneko can become nekomata with enough age and power. However, they have very different origins, and the stories behind both have changed over time. 


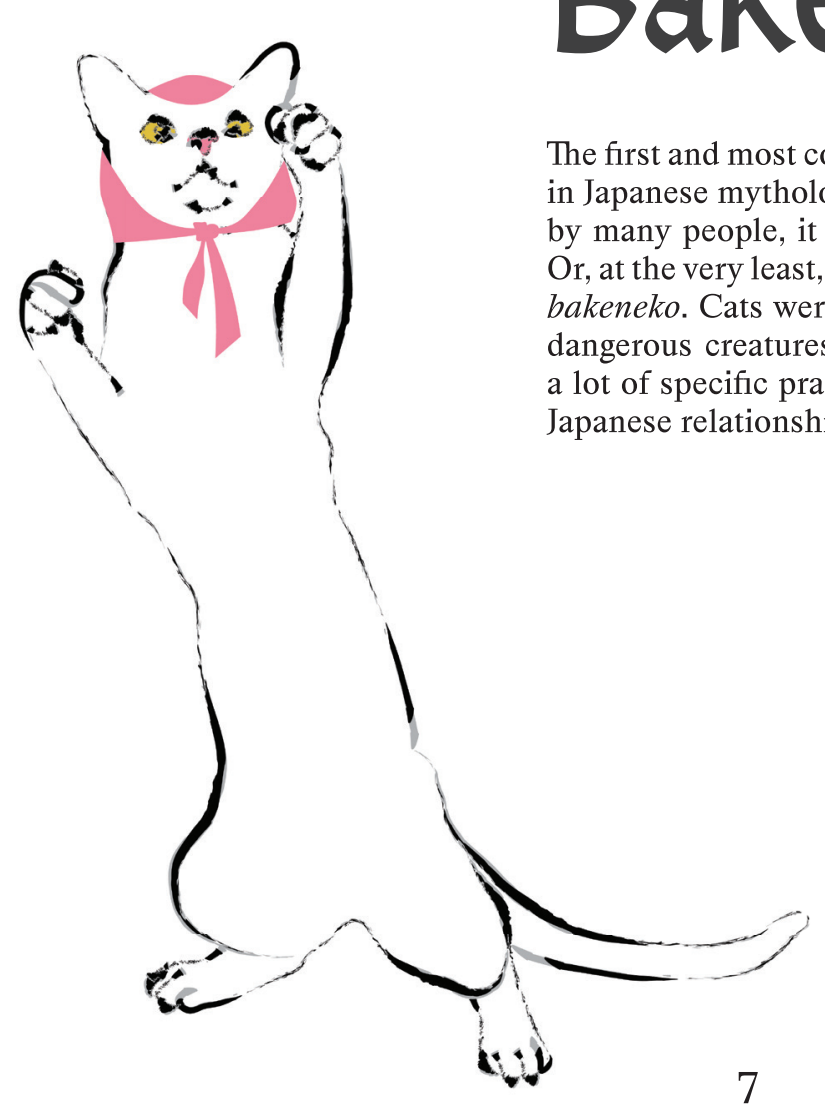

One of the most common beliefs about cats and bakeneko was that their power came from their tails. No one knows exactly a cat's tail was at housed a cat's power. The longer the tail, the more powerful the bakeneko. In some cases it was believed that the way to recognize a bakeneko was through the length of its tail, as only cats with very long tails were powerful enough to become bakeneko. As a result of this superstition, it was common practice for Japanese households to bob the tails of their cats at birth. In many ways this was considered a generous act, as it saved the cat from becoming a demon. However, there were still other precautions taken.

Another common superstition about bakeneko was that they were very old cats. It was neko was that they were very old cats. It was
believed that cats would become bakeneko believed that cats would become bakeneko only when they had reached a great age, at
which point their power would become so strong that they would become bakeneko. A common practice which arose from this was a custom of getting rid of cats once they reached a certain age. The exact age varied by region. In some places it was commo to get rid of cats when they reached three years old This practice came from a famous years old. This practice "cane from a famous proverb which stated. "Feed a dog for three days and he will remember your kindnes for three years. Feed a cat for three years and she will forget your kindness

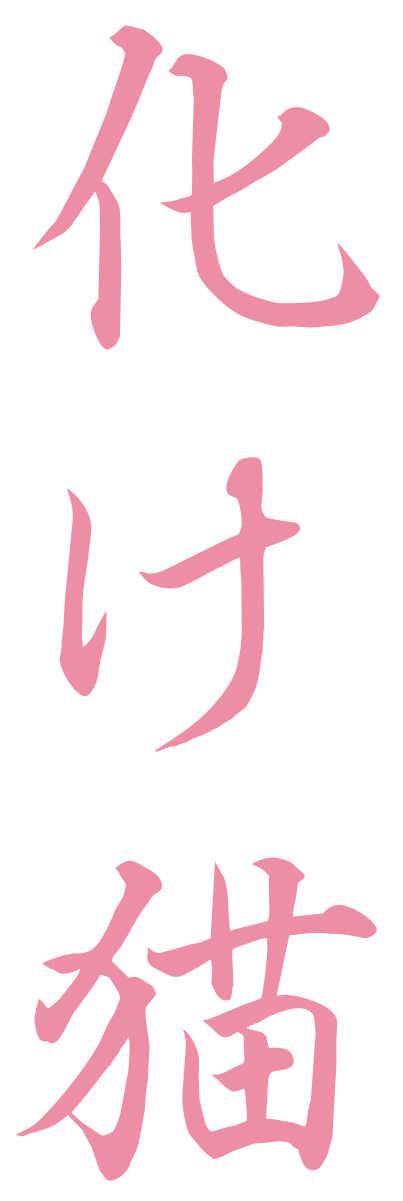


days." This proverb was commonly cited as a reason not to trust cats, but in some regions it was taken quite literally, meaning that a cat could not be trusted beyond three years. In other provinces however, the age at which a cat should leave a family was thought to be much older. Some people believed cats over the age of ten were not to be trusted, and in other regions the age was as high as thirteen years. Some claimed that a cat should never be cast out, for fear of them returning to exact revenge. In these cases, it was believed that a cat would leave on its own accord after the appropriate amount of time had passed as it respected the family enough to know what had to be done.

These superstitions may seem extreme, but they came from a real fear of what would happen once a cat became a bakenek. They were not usually considered to be gracious or benevolent creatures. Bakeneko were thought to cause all sorts of mischief, ranging from reanimating corpses to feeding vampirically on the blood of men who wronged them. Bakeneko were often thought to disguise themselves as women in order to prey on their husbands. In order to take on

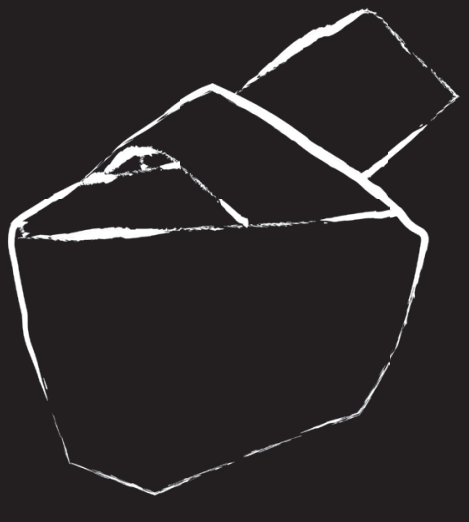

woman's appearance, a bakeneko had only o wrap the woman's towel around its head and dance around on its hind legs. It would then use its disguise to kill and feed on the woman's husband. If a person in a household should die, they should not have by any means been left alone with the cat. If the cat jumped over the corpse, or ran under the raised coffin, it would impart its energy into the corpse and reanimate it as a va into This could be prevented as a vampire. sword across the corpse. 

later than the name itself. Nekomata were the first variety of supernat ural cat to appear in Japan, and originally they didn't appear to be particularly magical. They were originally said to be large cats which resided in mountainous regions and preyed on unfortunate passersby. The name nekomata was written as 猫また. 猫 or "neko" translates directly to cat, however また is hiragana, meaning it is written in a way that indicates promunciation rather than meaning まt just a way "mat " wichout any "thata," without any indication of what it might mean in inis context (this is because there are a number of words which are pronounced 又, which is often translated as "split cat" or "forked cat" 又, which is often translated as "split cat" or "forked cat," though a more literal translation is "again cat." It was around this time that the perception of nekomata shifted, becoming monster cats with split tail. rather than wild cats of the forest.

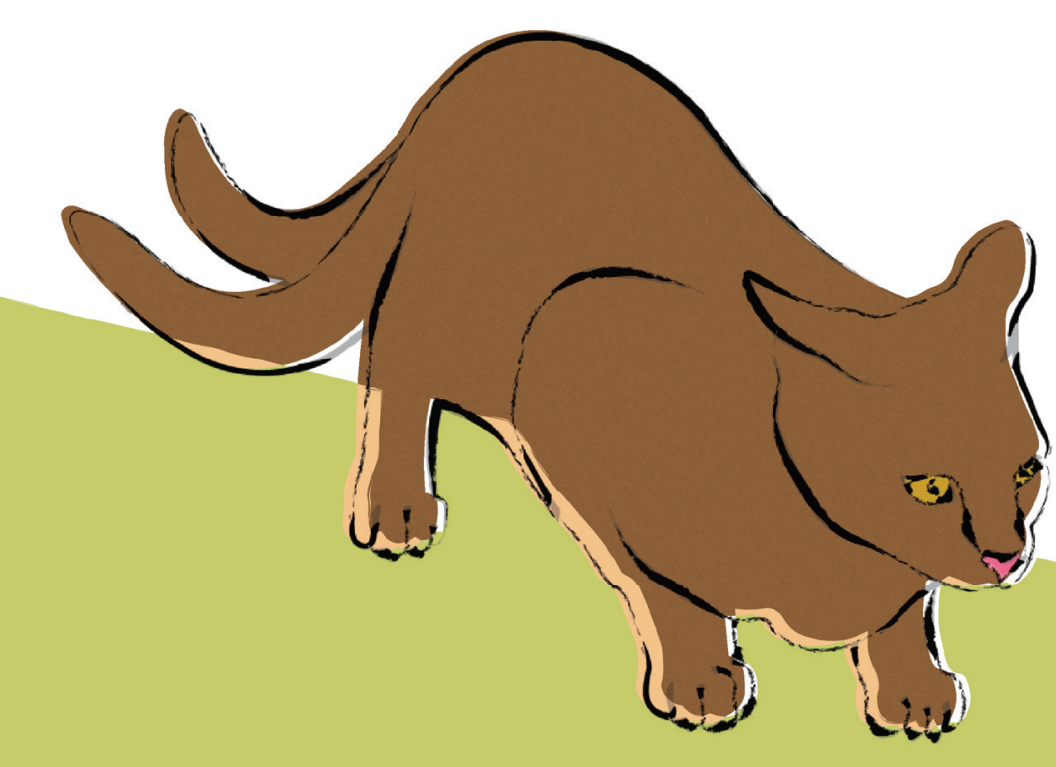

\section{Nekomata}

The second most common kind of supernatural cat to appear in Japanese folklore is the nekomata, or the "split cat"*. Nekomata are called split cats because they were believed to be very old cats who grew two tails (presumably because one was not enough to contain their power.) In most cases nekomata are cited as having evolved from bakeneko, and they are generally described as a more powerful version of them. Because of this, nekomata don't have many unique powers of their own, they just have elevated versions of the powers of bakeneko.

Just as bakeneko were believed to be cats who grew to a very old age, nekomata were thought to be bakeneko which bakeneko which reached an even greater age, at which point hey would grow to monstrous sizes and their tails (as well as their ears in some accounts) would split into two. This evolution is similar to that of the kitsune, or the Japanese fox spirit. According to folklore, the more tails a kitsune had, the older and more powerful it was. There are some accounts of fearsome nekomata with more than two tails as well, indicating that spirit animals in the Japanese tradition were generally thought to gain more tails as they gained more age and power. 
ily benevolent, but they were also not evil by any means,

except to the extent that all cats were believed to be. There

was a definite hierarchy in the favoring of cats in Japanese

culture. Though the specific order of this hierarchy varied

by region, there are socife defie simila

could argue were universal among the Japanese archipelago.

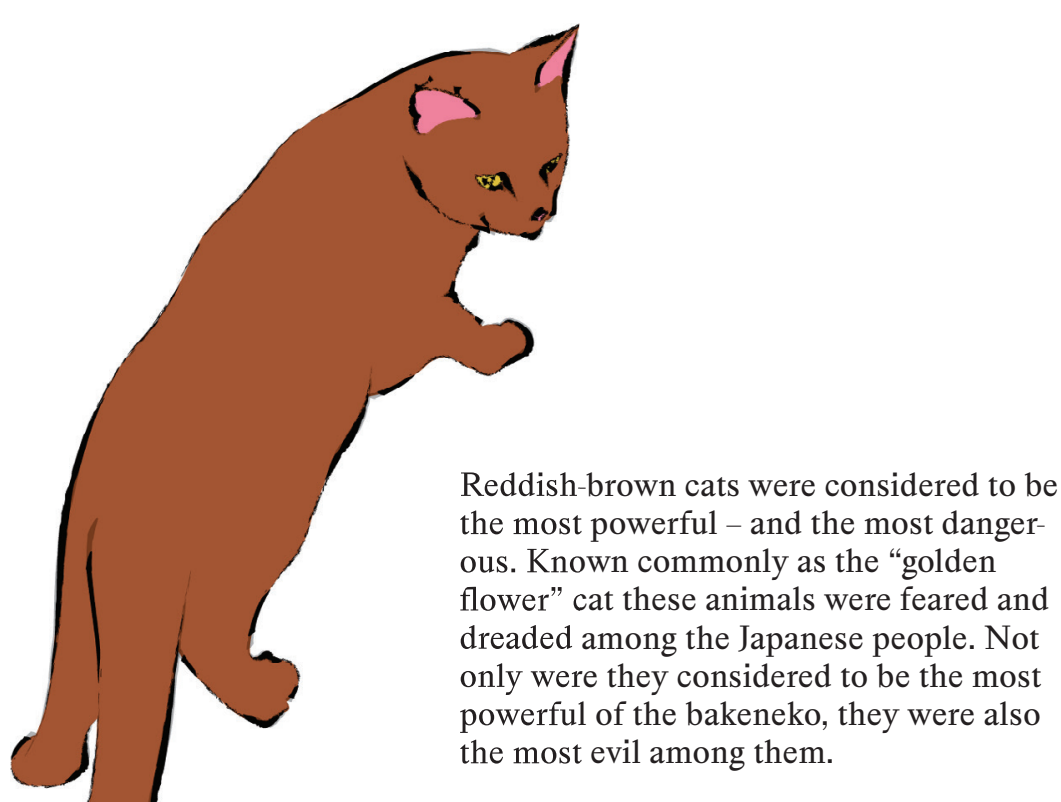

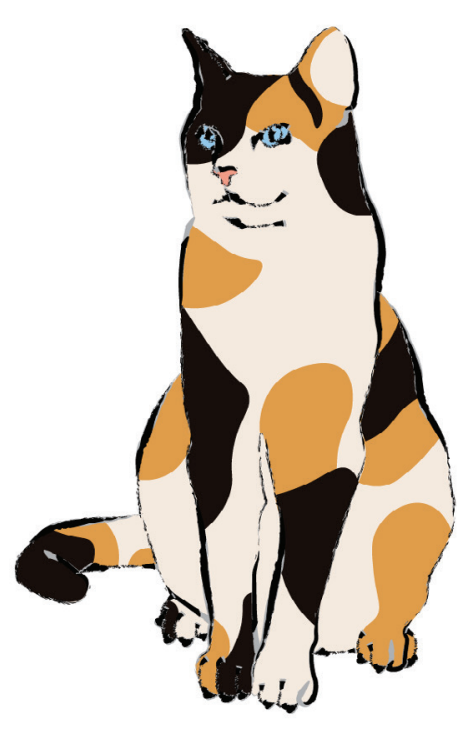

Black cats were actually among the few cats who could be generally trusted. They were not considered to be entirely powerful, nor entirely good, but they were thought to possess a very useful skill. In Edo period Japan, black cats were believed to have the power to foretell the weather. Because of this, many sailors kept black cats aboard their ships as a sort of barometer.

Calicos, or "tri-color" cats were considered to be almost as powerful as golden flower cats, but with one key difference: they were good. Calicos were thought to be one of the only Cat varies that cou the only cat varies that cond be onsted as a housecat, and many people thought they brought good luck. This is because they were thought to ward off bakemono, or spirits.

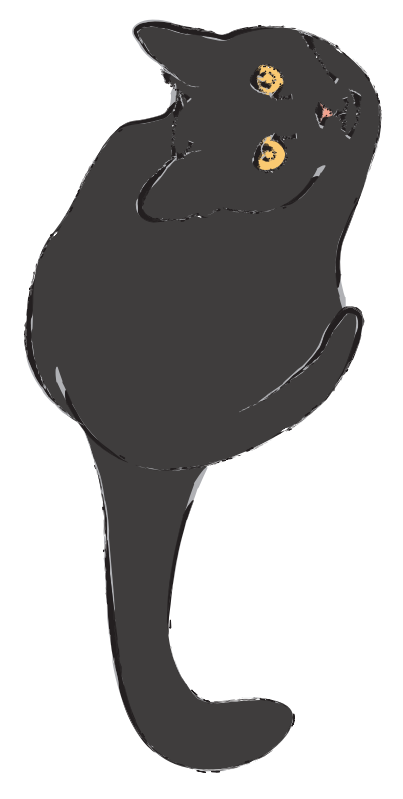




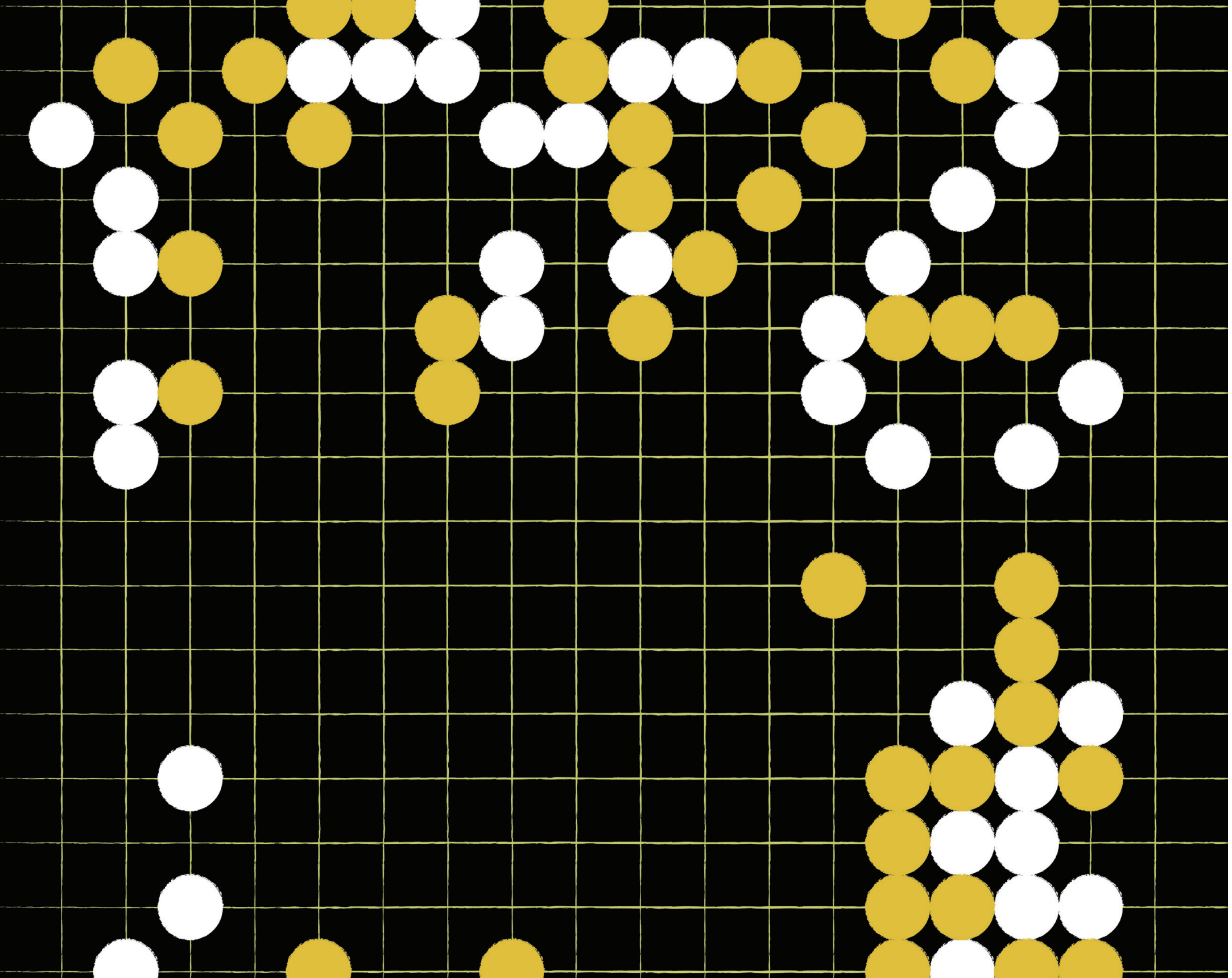

Kaibyo can appear as evil or benevolent creatures, depending on what stories you read. Generally speaking, bakeneko and nekomata were thought to be at least mischievous, and all tho we to be at lenekto and nekoms, and all kaibyo we co to stories tell of evil bakeneko, but many also tell of cats who served noble causes but were suspected of evil anyways. These stories usually end with the cat getting revenge on the person who wronged them, usually with their strong supernatural powers. These were cautionary tales, and they suggested a respectful view of cats rather than a fear based one. Cats were not to be trusted, but they were to be treated with respect, and they should never be crossed.

One such story tells a tale of a cat who the woman's most cherished cat, and she took it with her wherever she went. One day she was walking with a samurai, with the cat walking beside tiom a sam very sthan as usual. The cat began alking betweenge, meowing loudly and walking suspicious of thes legs. The samurat gew cut its head off with his sword. The cat's head 
flew up to the ceiling where it caught in its to drop on the lady's head The samurai realized he had made a terrible mistake, as the istake, as the cat had on been trying to warn of danger. The woman mourned its death so greatly that a shine was dedicated to it. In this story, there is no vengeance at the end.

Another story, a version of perhaps the most famous bakeneko tale, The Vampire Cat of Nabeshima, tells of a cat who avenges his owner. The story tells of the feudal lord Nabeshima, who liked to play goh with a particular blind man, and this blind man had a pet cat. One day, the blind man beat Nabeshima repeatedly and in his rage, Nabeshima recapitated the man. When the Nabeshina decapitated and in news of his death reache his mother, she urged the cat to do something to avenge his death. The cat then disappeared, and the mother didn't know what happened to it. The cat had gone to Nabeshima and was impersonating one of his favorite mistresses so as to slowly drain his life force. In the end the cat's mission is foiled by a loyal retainer, but this story offers an interesting example of a slightly different view of cats. This cat was loyal to his master, to the point that it was loyal to his master, to paist were known to hold grudges in Japanese

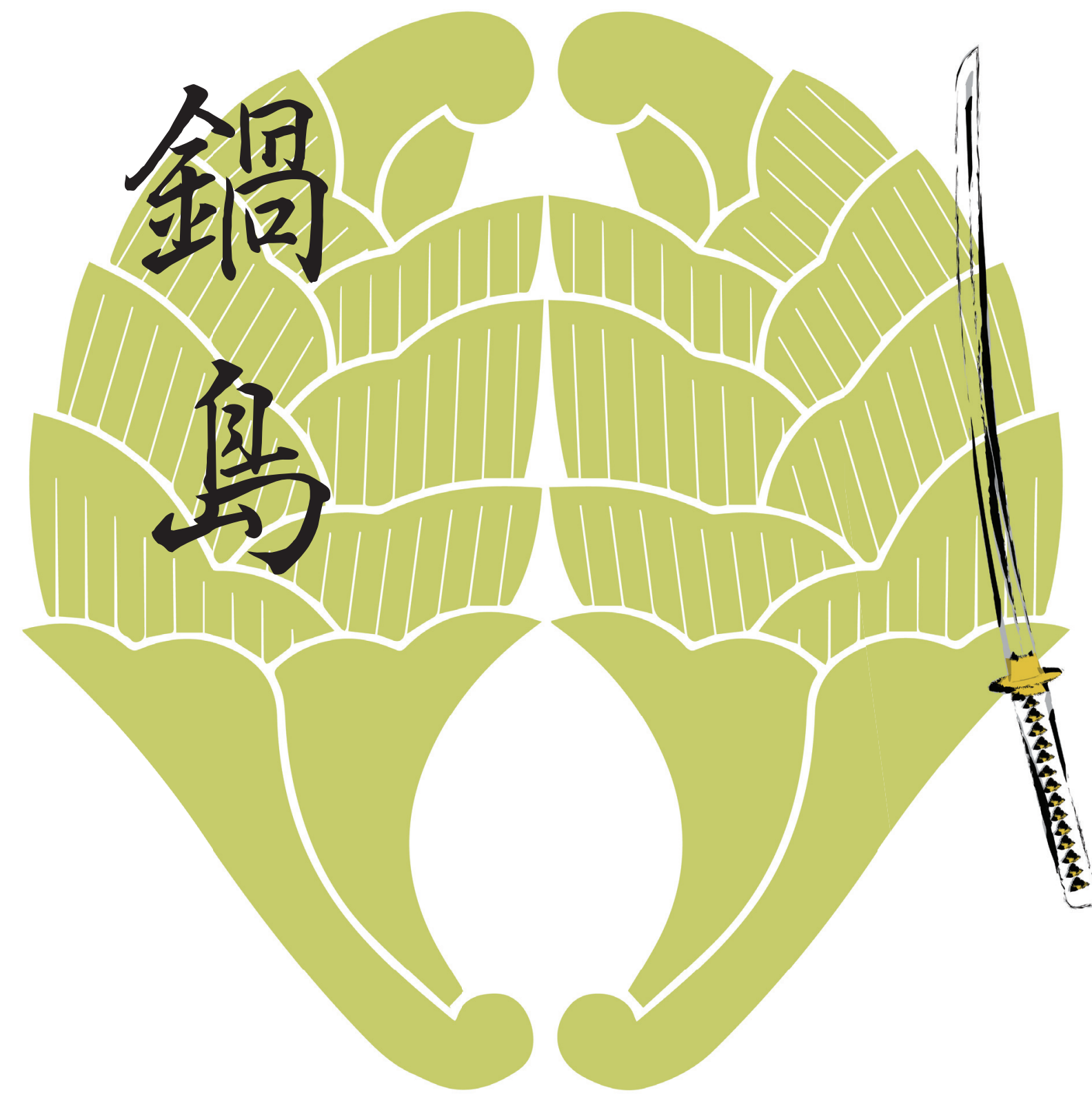

mythology, one of many reasons that people were advised not to cross them. But this story offers an interesting example of the ambiguous morlity of these supernatural cats. The cat was only trying to ight awrong which had been conly tring to right a wrong which had been committed against an innocent man, but was stopped in the end by a noble guard. Was the cat in the wrong? Or was it acting morally?

As you can see, not all accounts cite cats or bakeneko as truly evil. This is in part because of Japan's traditional cultural views on morality, wherein there isn't a strict line drawn between good and evil the way there is in the West.

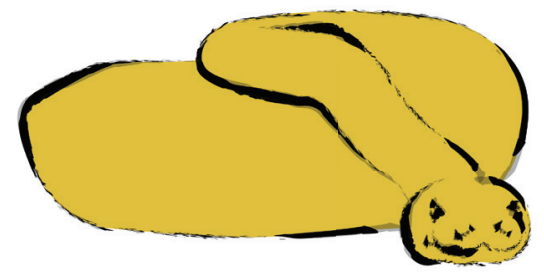


Exigins of Beliets 
On Naturally Mysteríous Traits

A fairly universal reason why cats are perceived as supernatural creatures comes from their very natural behaviors. Anyone from their very natural behaviors. Anyone
who has or has had a cat will understand who has or has have strange little quirks that can why. Cats have strange little quirks that can
be off putting to people. The way they stare be off putting to people. The way they stare at you, the way they silently creep around like they're hiding something. The way they just seem to appear in strange corners. Cats
are inherently mysterious. It is said that the creation of superstitious beliefs surrounding cats in Japan coincided with their becoming common and widespread. More peopoming them acting according to their natue, saw then acting according to their nature, independently, and suddenly they were not seen as so wonderful and charming.
One notable myth that has come about as a result of cats' behaviors is the very common belief that a bakeneko or nekomata's power comes from its tail. As I described in a previous section, it was believed by many that a cat's power resided in its tail. This belief was so widespread that it became common practice to bob, or cut off, a cat's tail at birth. It is speculated by many that this is a direct result of the way cats play with their tails. If you've ever had a cat, you might have noticed that cats have a strange habit of chasing their tails. It can be off putting to watch however, because the cats don't seem to be aware that the tail is a part of them. They stalk, watch, and pounce on their tails as if it's a bird or rodent they'ce chasing. Once they catch the tail, many cats will chew on it like they've caught their prey. This behar it like they've ing to many Japase folk of the tine, and ing to many Japanese folk of the time, and they began to speculate on why cats would act this way. Was the tail not a part of the cat at all? Perhaps it was a demon which attached itself to the cat, waiting for the right moment to take it over completely. There is also the fact that a cat's tail was thought to resemble a snake. Snakes were considered bad luck in Japan, so the serpenine nature of the appendage, saired with the strange behaviors cats exhibited with them, stang perfect recipe for superstition. 


\title{
Specific Myths
}

Though it may seem obvious, one of the key categories we can see behind the origins of cat myths relates to specific instances which were retold and fantasized. In short, we can trace some stories and beliefs back to very specific origins.

For example, a common belief about cats duringthe Edoperiod was tuck to see a cat drinking oil from a lamp. This may sound like strange and off putting behavior, but the reason cats did this is actually fairly simple. At the time, the most common fuel for lamps was fish oil. In this era, cats were typically just fed whatever leftovers their owners had, which more often than not was just grains and vegetables. It's easy to understand why a cat, who is an obligate carnivore, may crave the rich fattiness of fish oil. Now imagine looking up in the night to see yow at standing on your cat standing on its hind legs, lapping at oil and illuminated consider the possibility that bad luck might have befallen this person the next day, it's easy to see how connections were made and a rumor may have been started. This belief could a to he contributed to the common could also have contributed to the common myth that bakeneko would stand on their hind legs and sometimes dance about when they were doing something mischievous. This particular story may contain a lot of speculation, but not all origins are so open to interpretation.

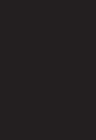

(a)
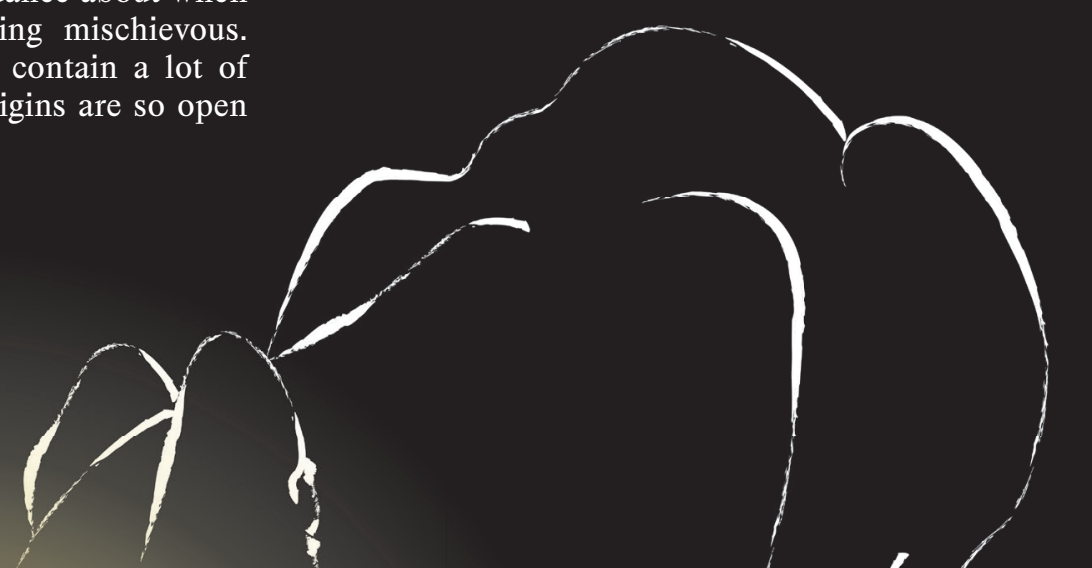



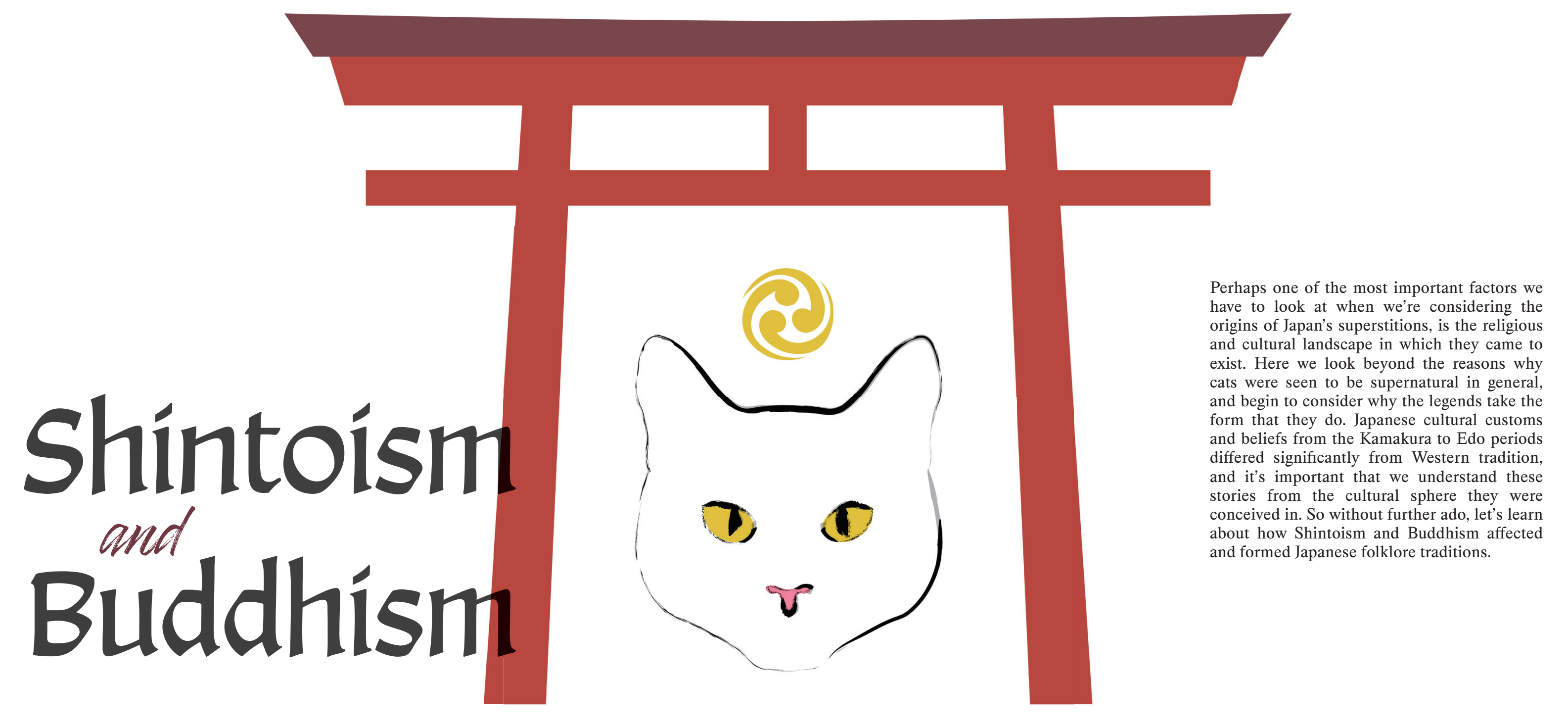




\section{Natural Hierarchy}

The first thing that it's important to under stand in terms of Japanese culture and religion is the perceived relationship between the three realms of existence: Nature, Man, and God. To begin, we have to understand the Western thing, as that is the perpective that three things, as that is the perspective that many of us have ucons Judeo-Christian tradition, there is a definite hierarchy between these three groups, and that order is based on two dichotomies that we have created. The first is material versus spiritual, and the second is finite versus infinite. When these traits are taken into account, there emerges a clear hierarchy in Western thought. Nature, which is finite and material, takes the lowest rung Above it is Man, which is finite but ruiritual, and it the very top of the hierarcy is God, and at the very top of the hicrarchy is God, who is both spiritual and infinite. There is a strict and unchanging hicrarchy in this relationship. Something cannot exist in multiple

groups, and that made the pecking order in udeo-Christian cultures quite clear. This is something that most people living in the Western world inherently understand. But this is not the way that these relationships are viewed in all parts of the world, and there is no tradition that proves this quite like the Japanese. 
In Japan, these three groups were (and in some cases are) still considered to exist, but the relationships between them were interpreted in an entirely different way. Japan's cultural and religious beliefs have been largely shaped by the Japanese lan scape, which is nothing if not an ever-changing world, prone to natural disasters and seasonal changes. This can be evidenced in the way Japanese cuisine has developed, as a tradition which relies heavily on the seasonal availability of different fish and vegetables. This is all to say that the Japanese did not have a strong concept of the definite. Change and impermanence is at the core of both Sintor the traditis Japan from which tration Japan from which most folklore sprung, and Buddhism, as it existed in Japan. This can even be seen in the Japanese language itself, where the meaning of words can change drastically depending on context. This led to an equally fluid perception of the rela- tionships between things. And here's where we return to those three realms of existence. The Japanese similarly believed in Nature, Man, and ever-changing cast of spirits. This, howerer, shere the similarities stop. The Japares believed that all of these gop. The Japanese believed that all of these groups existed on the same plane of existence, the same level if you will, in contrast to the hierarchy of he West. They also shared many qualities. "God" was really kami, which described everything that was thought to be beyond understanding. Mt. Fuji was considered a kami. Nature could be kami, as it was inherently spiritual. All groups were both finite and infinite. There was a sense of oneness between all these groups. And because these groups were not strictly defined, nor were they considered definite by our understanding it was considered relatively common for there to be "slippage" between these groups. the to be "slippage" between these groups. The animal form was temporary, as was any other form, so a cat might turn into a spirit, a spirit into a man, or any other possible transition. Some creatures might exist between certain groups, straddling the line between the natural world and the spirit world. This is a line that bakeneko were thought to cross between frequently. This equal playing field also led to a sense of neutrality in the relationships, which translated to a feeling of mutual rect. This is why cats were treated mestects they pleased, than they wo come and go as person or family owned. 


\section{Blurred Lines of Morality}

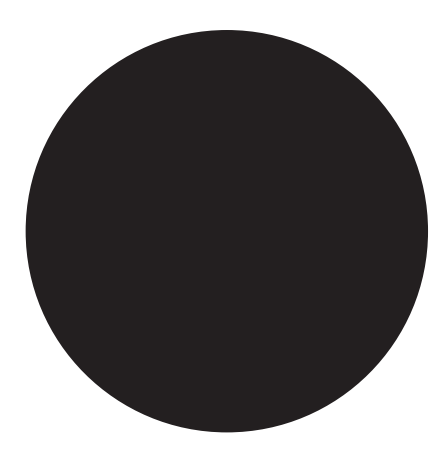

Another important cultural tradition we have to dissect to really understand what role kaibyo play in Japan is the Japanese tradition of morality. This is another area we Westerners can't fully grasp without consciously changing our lens. In the modern day, it's likely that many Janes grasp this traditional concept of mont can't grasp this traditional concept of morality, as Western culture has had a strong influence on Japan's development. But it's another area that's critical to the understanding of supernatural creatures, cats or otherwise, in Japanese folklore. Japan's sense of morality can actually be related back to the sense of hierarchy, or lack thereof, that we talked about before. But once again, we first have to briefly go over the general form of morality that we have in the West.

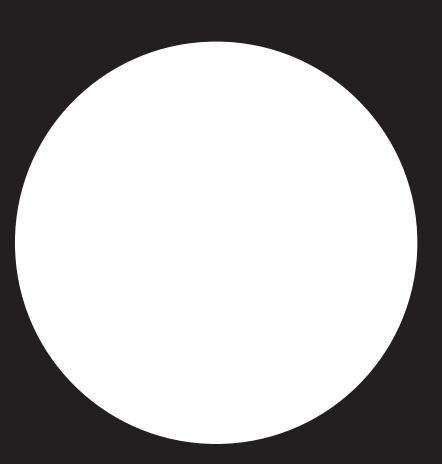
will as well as intellect, we should in theory know what we should and shouldn't do, and we have the power to act accordingly. And because we have God, a an infile being who holds a definite place aboves in who holds a definite place above us in the natural hierarchy of things, a "sin" or wrongdoing is primarily seen as such because it defies God's will. But here we get into the fundamentals of what makes something a sin. Firstly, the person must be aware of the fact that they are going against God's will. Accidentally defying Him is not punishable, as the person had no intention of committing a sin. The second qualifier is that the ting a sin. The secto qualifer is that the person had the option not to commit the sin. Whis once againg Western lens, intent and morality are inextricably entwined. If a person has evil intentions, they commit evil deeds, but if they have good intentions, they cannot be held accountable. This is something we instinctively understand in the West. But Japan had a very different structure. 



\section{How it All Relates}

At this point I'm sure you're wondering how all of this abstract talk about Japanese religious traditions relates to the origins of bakeneko, but I assure you that they do. It may not directly relate to the specific myth surrounding bakeneko, but we can certainly see the influences of these traditions in the stories that came to be about supernatural cats in Japan Japanese morality while looking at these stories, we can come to have a deeper unde standing of the attitudes that these creatures were regarded with. Like I said before, bakeneko were not necessarily good or bad. They committed mischievous acts, sometimes good, but sometimes evil by nature. Ye there was no general commitment to these creatures being from as not black and white (good an bad), there was instead a sense of respect. Bakeneko were fearsome, yes, but they we also just another creature which existed in the world. This concept is much easier understood when it's regarded through the lens of traditional Japanese morality. More than anything bakeneko were powerful, and than any that power conld be directed in any number of ways, meaning the only important thing to remember was that you shouldn't get on their bad side.

By examining the traditional interpretation of spiritual hierarchy in Japanese culture, we can start to understand the place bakeneko and other kaibyo hold in Japanese culture. Bakeneko are by no means the only supernatural animal which the Japanese believed in, and we can see now that from the standpoint of Japanese religion it's natural to point of Japanee re religion hift beteved that certain shift between states of being. In the same way that many her by believed to. It's only by looking at all of these cultural influences that we can truly understand the environment which fostered these superstitions. 
2n $n$ r n $n$

nan

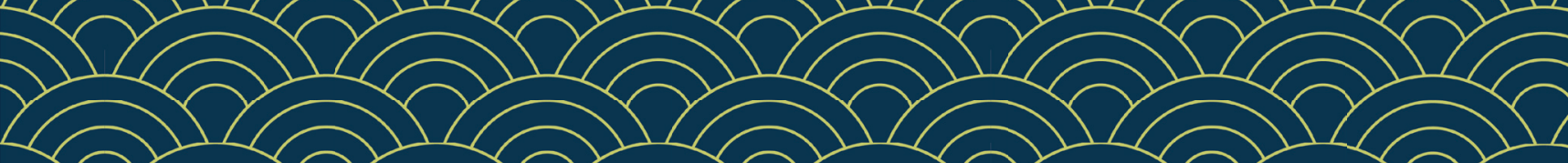

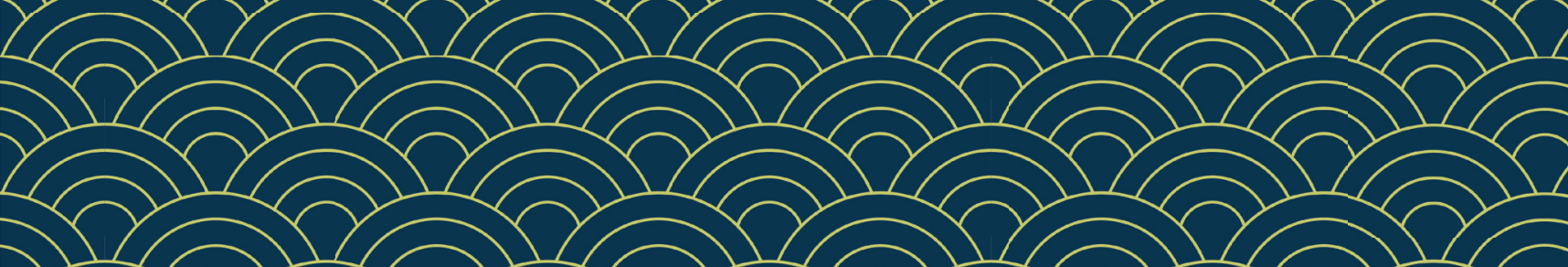
mann nैan * 27 2 舟 